\title{
A procedure to evaluate the indoor global quality by a sub objective-objective procedure
}

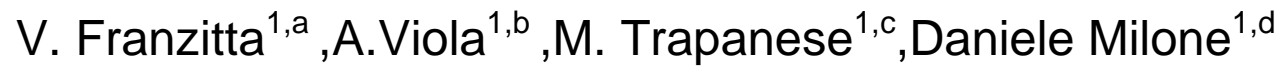 \\ ${ }^{1}$ DEIM - Dipartimento Di Energia, Ingegneria Dell'informazione, E Modelli Matematici, University of \\ Palermo, Palermo 90128, Italy

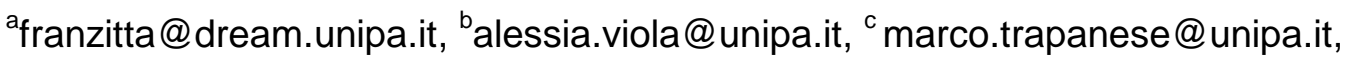 \\ daniele.milone@unipa.it
}

Keywords: comfort; indoor; global comfort

\begin{abstract}
This paper proposes two complementary procedures for assessing the indoor global comfort: the first one, prevalently objective, is based on the acquisition of microclimate measured data and computed subjective values; the second one, that is purely subjective, uses a questionnaire drawn from the ISO/DP 10551 Recommendation. An application to some lecture-halls is here showed
\end{abstract}

\section{Introduction}

Comfort and health protection within the work areas requires environmental conditions in accordance with standard values and/or sanitary limits of some descriptors linked to physical phenomena like heat, light, sound, odour, colour and so on. Scientific papers and rules, however, separately consider the impact produced by the single parameters. Some researchers, recognising that people experience effects of various and combined factors, have begun compared surveys of the discomfort from heat, noise and vibration, colour and noise, indoor air pollution, heat and noise [1,2], etc.. This paper is aimed at setting up composite descriptors of the global comfort throughout confined spaces by using mathematical tools developed and used in other fields of sciences [3-12]. Two complementary procedures are here proposed and applied to some lecture-halls in the university of Palermo. The first one, prevalently objective, is based on the acquisition of measured data and computed subjective values. The second one, that is purely subjective, uses a questionnaire drawn from the ISO/DP 10551 Recommendation [13] in order to assess the personal discomfort vote so to the single aspects and global exposition. In the statistical processing of results the regression analysis and fuzzy logic have been used [14].

\section{Results and Discussion.}

During various stages of design, construction and operation of a building is the primary importance the achieving and maintaining of an environmental quality for optimal indoor environments that characterize the building3. Experimental Section itself, meaning the environmental quality full compliance of the environmental system, expressed in terms of performance, the requirements of welfare (thermohygrometric, visual, acoustic, olfactory-respiratory) of the occupants. Most symptoms of disorder is essentially attributable to four possible causes: bad air quality, an uncomfortable thermal climate, excessive noise or an insufficient or excessive lighting conditions.

The Objective procedure assumes as its survey tool the provisional method (or objective analysis methodology) which is based on the measurement of the main indoor environmental microclimate parameters referring to the various aspects of applied technical physics: air temperature, relative humidity and velocity; globe temperature; horizontal illuminating and noise level. In this connection we individuate some descriptors like radiant mean temperature, Predicted Mean Vote PMV, Predicted Percentage of Dissatisfied PPD, Wet Bulb Globe Thermometer WBGT whose values deduced from the experimental data set can be compared with the corresponding limit thresholds fixed by specific rules or recommendations in such a way to assess the actual comfort conditions. 
The second assessment methodology is subjective type and uses as a basis the questionnaire provided by the rule ISO/DP 10551 [13]. This procedure has been applied for estimating the effects of various environmental factors upon the hygrothermal comfort conditions. The primary structure of the aforesaid questionnaire contains a big set of questions about the considered single aspects (11, 5 and 8 respectively for the hygrothermal, acoustical and visual sections) and 2 for expressing the personal global judgement. A detailed analysis of the formulation allows reducing the interview contents to 13 questions with unique standardized replays attributing to each one a numerical codex (vote).

These scales do not homogeneous each other: some list 7 judgement degrees, some 4 . We note also that the scale of thermal sensation is straightforth in relation with the scale of PMV.

\section{Experimental Section.}

On September 2011 a wide study throughout the Engineering Faculty in Palermo, assessing the global comfort within indoor spaces devoted to university education, has been performed. A sample of five lecture-halls, 4 belonging to the Department of Energy (D.E.) and 1 to the Department of Electrical Engineering (D.E.E.), was considered in various hour belts during and without a lesson. Both the physical and subjective surveys were carried out acquiring information and data about the microclimate and subjective parameters.

A measurement station type BABUC/A by LASTEM was equipped with sensors for detecting experimental values of hygrothermal parameters in conformity with the ISO 7726 Recommendation. Noise climate and spectrum field were analysed by a integrating sound level meter ONO SOKKI type LA-5110, whose functions allow to analyze sound situations and physical configuration also complex.

Horizontal illuminating upon the work plane was measured by a digital luxmeter EXTECH INSTRUMENTS that uses a selenium photoelectric cell. We note that the temperature values provided the globe thermometer allow to calculate other main comfort indicators like the radiant mean temperature tmr, basic for deducing the PMV and WBGT, and the operative temperature top. For PMV assessment we assumed values of 0.6 clo and 1.2 met respectively corresponding to summer clothes and light sedentary activity. For each sample element (lecture-hall) was obtained an experimental card. In Table 1 we report the collected data referring to the various lecture-halls while in Table 2 the statistics of both the measured and calculated quantities.

Table 1. A synthesis of the experimental survey. Microclimate conditions for each lecture-hall.

\begin{tabular}{|c|c|c|c|c|c|c|c|c|c|c|}
\hline AMBIENTE & $\mathbf{t}_{\mathbf{a}}$ & $\mathbf{t}_{\mathbf{w}}$ & $\mathbf{v}_{\mathbf{a}}$ & $\boldsymbol{\varphi}$ & $\mathbf{t}_{\mathbf{g}}$ & $\mathbf{t}_{\mathbf{m r}}$ & $\mathbf{t}_{\mathbf{o p}}$ & $\mathbf{P M V}$ & PPD & WBGT \\
\hline $\mathrm{A}(\mathrm{DE})$ & 27.14 & 27.19 & 0.04 & 57.5 & 27.81 & 28.2 & 27.58 & 1.09 & 30.48 & 27.40 \\
& 27.00 & 27.14 & 0.00 & 57.9 & 27.80 & 28.07 & 27.50 & 1.08 & 29.89 & 27.34 \\
\hline B (DE) & 27.40 & 27.70 & 0.01 & 59.7 & 27.68 & 27.75 & 27.58 & 1.12 & 31.54 & 27.70 \\
& 27.20 & 26.50 & 0.00 & 59.5 & 27.00 & 27.05 & 27.13 & 0.99 & 25.94 & 26.65 \\
& 25.67 & 25.17 & 0.00 & 56.6 & 26.67 & 27.04 & 26.35 & 0.72 & 16.04 & 27.02 \\
\hline $\mathrm{C}$ (DE) & 25.20 & 25.73 & 0.02 & 57.1 & 26.60 & 27.16 & 26.18 & 0.66 & 14.30 & 25.99 \\
\hline F (DE) & 25.80 & 26.73 & 0.01 & 56.4 & 26.80 & 27.18 & 26.49 & 0.76 & 17.24 & 26.75 \\
& 25.70 & 26.68 & 0.01 & 57.0 & 26.78 & 27.18 & 26.44 & 0.75 & 16.86 & 26.71 \\
\hline A (DEE) & 24.70 & 25.55 & 0.04 & 55.0 & 25.80 & 26.22 & 25.46 & 0.44 & 9.17 & 25.63 \\
& 24.50 & 25.34 & 0.00 & 55.3 & 25.64 & 26.10 & 25.30 & 0.40 & 8.34 & 25.43 \\
\hline
\end{tabular}

Table 2. Mean microclimate conditions for the whole sample.

\begin{tabular}{|c|c|c|}
\hline PHYSICAL QUANTITY & MEAN $\boldsymbol{V A L U E}$ & STANDARD DEVIATION \\
\hline Air temperature $\left({ }^{\circ} \mathrm{C}\right)$ & 25.59 & 1.12 \\
\hline Wind speed $(\mathrm{m} / \mathrm{s})$ & 0.01 & 0.02 \\
\hline Relative humidity & 56.66 & 1.75 \\
\hline Mean radiant temperature $\left({ }^{\circ} \mathrm{C}\right)$ & 26.73 & 0.55 \\
\hline Operative temperature $\left({ }^{\circ} \mathrm{C}\right)$ & 26.18 & 0.76 \\
\hline Horizontal illuminating $(\mathrm{lux})$ & 298.51 & 6.14 \\
\hline Noise equivalent level $(\mathrm{dBA})$ & 52.0 & 6.15 \\
\hline
\end{tabular}


The questionnaire provided by the rule ISO/DP 10551 was distributed to a sample of 300 students (245 male and 45 female) of age within the interval 19-28. All the interviewed correctly compiled the questionnaire and the global results are resumed in Table 3.

Table 3. Frequency distribution of the whole sample. Palermo, September 2011. Mean Value V, standard deviation $\sigma$.

\begin{tabular}{|c|c|c|c|c|c|c|c|c|c|}
\hline \multirow[b]{2}{*}{ SCALE } & \multicolumn{7}{|c|}{ SUBJECTIVE VOTE } & \multirow[b]{2}{*}{ V } & \multirow{2}{*}{$\sigma$} \\
\hline & -3 & -2 & -1 & $\mathbf{0}$ & +1 & +2 & +3 & & \\
\hline 1 & 0 & 1 & 20 & 69 & 116 & 75 & 14 & 0.97 & 0.990 \\
\hline 2 & - & - & - & 81 & 168 & 40 & 6 & 0.90 & 0.695 \\
\hline 3 & 3 & 59 & 148 & 74 & 6 & 5 & 0 & -0.88 & 0.844 \\
\hline 4 & - & - & - & 145 & 118 & 30 & 2 & 0.62 & 0.643 \\
\hline 5 & - & - & - & 71 & 117 & 93 & 14 & 1.17 & 0.848 \\
\hline 6 & - & - & - & 95 & 129 & 66 & 5 & 0.94 & 0.782 \\
\hline 7 & - & - & - & 76 & 103 & 77 & 39 & 1.27 & 0.989 \\
\hline 8 & - & - & - & 136 & 119 & 36 & 4 & 0.69 & 0.736 \\
\hline 9 & 0 & 6 & 10 & 25 & 7 & 6 & 1 & 0.05 & 1.069 \\
\hline 10 & - & - & - & 135 & 139 & 17 & 4 & 0.63 & 0.657 \\
\hline 11 & 0 & 1 & 15 & 82 & 127 & 57 & 13 & 0.89 & 0.934 \\
\hline 12 & - & - & - & 157 & 115 & 18 & 5 & 0.56 & 0.687 \\
\hline 13 & - & - & - & 138 & 130 & 23 & 4 & 0.64 & 0.686 \\
\hline
\end{tabular}

It is interesting to put in evidence that the female students manifest a better acceptance both towards the single exposition (mean vote in the scale $4,8,12=0.75,0.82,0.69$ respectively) and global exposition (mean vote in the scale $13=0.71$ ). From the data reported in this section we can start a comparison between the two provisional and diagnostic methods. As regards the thermal field, we can refer to the parameter PMV or WBGT assumed like comfort indexes by the Recommendations ISO 7730 and ISO 7243 respectively.The average values of PMV shows a thermal condition in good accordance with the average vote recorded by the question $1(0.97)$ that traduces a thermal sensation ranging between the thermal neutrality and a weak warm. The value of PPD is near to the percentage of interviewed (11\%) who have replied to the question 4 with the judgements "acceptable with difficulty" or "not at all acceptable". Also average values of WBGT (26.28), that is lower than the limit of 33 fixed by the ISO 7243 for metabolism rates up to 1.11 met, confirms the degree of hygrothermal acceptance. The mean statement of 0.9 along the scale of thermal comfort (question 2 : comfort-slight annoyance) is coherent with the previous vote of thermal sensation (warm) and that of thermal preference (question 3 ) with a vote of - 0.88 (slightly more cool).

The Acoustical parameter LeqA $(52.0 \mathrm{dBA})$ is higher than maximum threshold prescribed by the W.H.O. (World Health Organization) for the buildings devoted to education activity. It agrees well with the perceived noise vote (question 5) "a little high" and the corresponding sensation of "slight annoyance" (question 6) declared by most of interviewed. The mean votes referring to the question 5 about the sound perception (1.17) and 7 about the sound preference (1.27) are coherent. The poor annoyance can be reduced according to the suggestion provided by the average reply to the question 7 , that is a noise "a little less high". The sound field has been evaluated prevalently acceptable with a mean vote of 0.64 to the question 8 and a percentage of $12 \%$ as regards the number of dissatisfied people.

The mean work plane horizontal illuminating of 298 lux falls within the interval recommended for visual tasks. However, a notable non uniformity of lighting was found partly due to the necessity of darkening for correctly using the luminous blackboard. From the detailed analysis of the compiled questionnaires we can observe that: 
- The indoor visual conditions are retained quite enough (mean vote of 0.05 to the question 9).

- To the previous opinion corresponds a preference for increasing a little the illuminating level, that allows to less strain the eyes, as the question 11 records a mean value of 0.89 .

- However a mean judgement of comfort has been expressed.

- From the foregoing we can consider confirmed the mean vote of visual acceptability expressed by the question 12 (0.56). In particular the percentage of interviewed people who have marked 1 or 2 is of $91 \%$.

The last result is exactly repeated in relation to the question 13 about the acceptance of the global environment, so putting in evidence a full correlation. The mean value of 0.64 expresses a vote of complete acceptance.

It is suitable to emphasize that the discordance verified between the experimental and subjective descriptors are probably due to some basic aspects:

- A larger number of sample elements (interviewed people and examined indoor areas), along with a well programmed space and time analysis, is required in order to obtain statistically significant results.

- The subjective survey tool (students) is not always the same and then we cannot consider as calibrated, being the audience for each lecture-hall linked to the various hour lessons.

- An inadequate interpretation of some questions or adaptation phenomena may have affected some replies.

\section{An approach to the global comfort.}

A routine procedure considers separately the hygrothermal, sound, visual, atmospheric, electro-magnetic, etc.. aspects deducing the comfort degree for each sector and setting up a global vote by a qualitative decision process. A conceptually correct alternative method requires the implementation of a new index or descriptor that is a function of the main guide-parameters for each aspect.

Obviously this last way is hard and impervious, especially because the parameters at stack clearly are not homogeneous and affect each other. Here we propose as an effective tool the correlation expression obtained using the results contained in the compiled questionnaire within a programmed subjective-objective survey.

By indicating with $\mathrm{V}$ the global vote, $\mathrm{V}_{1}, \mathrm{~V}_{2}, \ldots, \mathrm{V}_{\mathrm{n}}$ the single votes (explicit variables or guide parameters) for each environmental aspect, we assume as sensation linkage $V=f\left(V_{1}, V_{2}, \ldots, V_{n}\right)$. In this paper we applied two different procedures in order to estimate a model able to predict the environmental global comfort vote from hygrothermal, acoustic and visual votes. In the following the above mentioned input variables of the models correspond to $\mathrm{X} 1, \mathrm{X} 2$ and $\mathrm{X} 3$ respectively, while $\mathrm{Y}$ stands for the global comfort vote. The first procedure is a multiple regression method that allows to identify the variable that has more weight in the predict the level of general comfort, and the variables whose contribution is statistically significant and not simply related to random factors. This procedure estimates a linear model expressed by

$$
Y=b_{0}+b_{1} * X_{1}+b_{2} * X_{2}+b_{3} * X_{3}+\text { err }
$$

where err $=0.47$ and b0, b1, b2 and b3 are the model parameters and err is the residual component of the model. To evaluate these parameters we have minimised the expression

$$
\sum_{i=1}^{N}\left(y_{i}-b_{0}-b_{1} * X_{1 i}-b_{2} * X_{2 i}-b_{3} * X_{3 i}\right)^{2}=\min
$$

where $\mathrm{N}$ is the sample dimension and yi, $\mathrm{X} 1 \mathrm{i}, \mathrm{X} 2 \mathrm{i}$ and $\mathrm{X} 3 \mathrm{i}$ are the values of the $\mathrm{i}$-th observation as regards the output and input variables (votes). The result of the procedure is represented by the expression: 


$$
Y=0.08+0.223 * X_{1}+0.224 * X_{2}+0.468 * X_{3}
$$

The second procedure allowed to build a fuzzy model according to the approach proposed by Takagi and Sugeno [14]. The model identification algorithm permits to select the variables that form the premises and, consequently, to evaluate the premise and consequent parameters.

The estimated model is constituted by four fuzzy rules expressed by the graphical representation of the following figure where two fuzzy subsets are defined on the variables $X_{1}$ and $X_{2}$ and no fuzzy set is defined on the remaining variable.
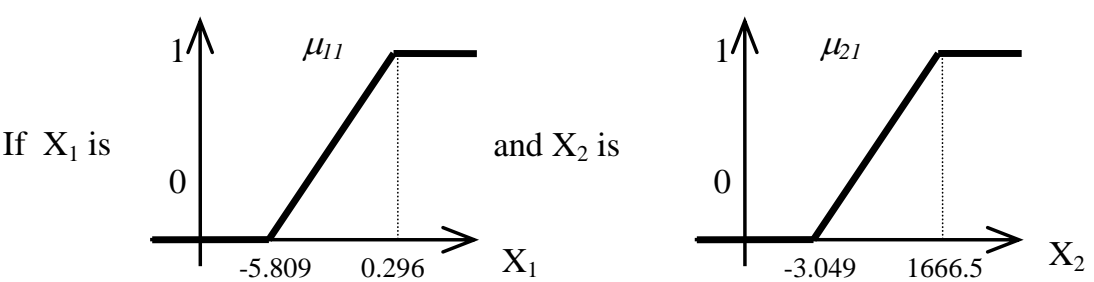

$$
\text { then } \quad \begin{aligned}
k_{l}= & -30705.28-741.65 \mathrm{X}_{1}+ \\
& +55.46 \mathrm{X}_{2}+1.36 \mathrm{X}_{3}
\end{aligned}
$$
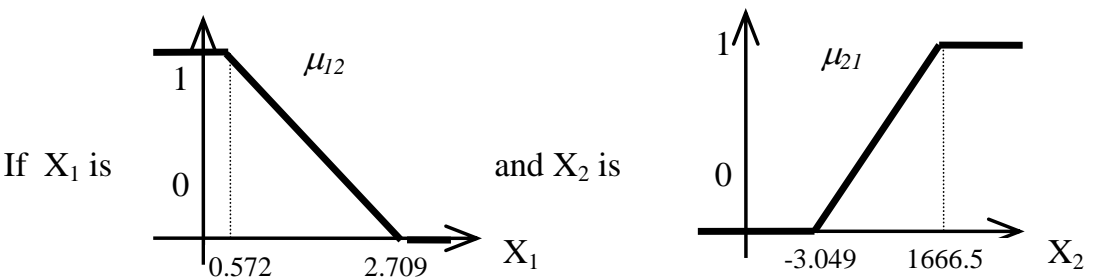

$$
\text { then } \begin{aligned}
k_{2}= & -28.08-30.06 \mathrm{X}_{1}+ \\
& +1.25 \mathrm{X}_{2}+0.33 \mathrm{X}_{3}
\end{aligned}
$$

If $\mathrm{X}_{1}$ is
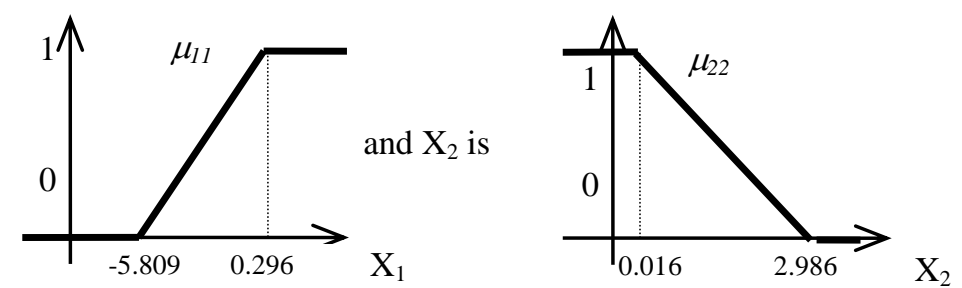

then $k_{3}=10230.84-254.13 \mathrm{X}_{1}+18.84$ $\mathrm{X}_{2}+0.69 \mathrm{X}_{3}$

If $\mathrm{X}_{1}$ is
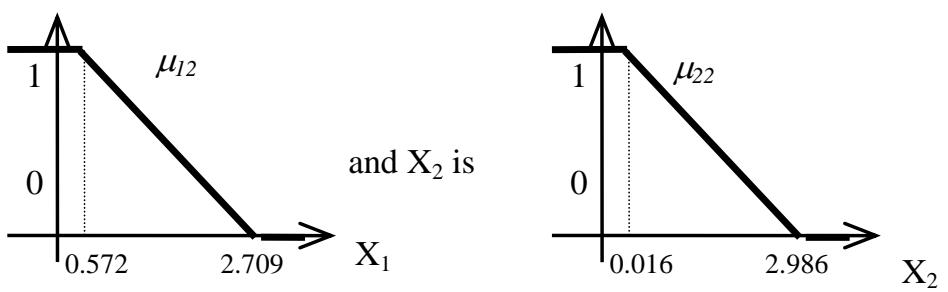

then $k_{4}=15.77-19.73 \mathrm{X}_{1}+$ $+0.02 \mathrm{X}_{2}+0.73 \mathrm{X}_{3}$

Each rule gives back a value for the output ki $=f\left(X_{1}, X_{2}, X_{3}\right)$, to which is associated a degree of truth given by $\mathrm{ki}^{*}=\min [\mu 1 \mathrm{j}(\mathrm{X} 1), \mu 2 \mathrm{k}(\mathrm{X} 2)] . \mu 1 \mathrm{j}$ and $\mu 2 \mathrm{k}$ are the membership functions characterising the fuzzy subsets defined on X1 and X2. In order to estimate the fuzzy algorithm's output, it is necessary to apply a defuzzyfication method as for example the centroid one:

$\bar{y}=\frac{\sum_{i=1}^{4} k_{i} k_{i}^{8}}{\sum_{i=1}^{4} k_{i}^{*}}$

To test the model fit, a performance index is estimated and defined as

$E_{r}=\sqrt{\frac{\sum_{i=1}^{W}\left(y_{i}-\overline{y_{i}}\right)^{2}}{N}}$

where yi are the values of output data and are the estimated values. We obtained for the linear model a performance index PI $=0.474$, while for the fuzzy model $\mathrm{PI}=0.437$.

\section{Conclusions.}

Finally it is demostrated that the processes of regression used, besides confirming the reliability of the subjective data collected, permit to identify the variables that have more weight in the evaluation of global comfort. 
The proposed target is to know statistically which aspect (thermal, acoustic, lighting, air quality etc) should be a priority action in any recovery global environmental, and find reliable answers in the made analyses. We emphasise that in literature a unique descriptor is not available that is able to express the global comfort level, for example providing the percentage of dissatisfied people as to an ambient considered as a whole analogously to that already ascertained for the single aspects of applied physics.

\section{References}

[1] Clausen, G., Carrick, L., Fanger P.O., Kim, Sun Woo, Poulsen, T., A comparative study of discomfort caused by indoor air pollution, thermal load and noise. Indoor Air 1994, 4, 255-262.

[2] Barbaro,S.; Bonanno,A.;Patti, B.; Mazzola, S.; Franzitta; V.; Grippaldi, V. Acoustical aspects of the environmental control. An effective tool for a sustainable urban planning., Proceedings of the the 2nd European Conference REBUILD, Florence, Italy, April 1998.

[3] Franzitta, V., Rizzo, G.. - Renewable energy sources: A mediterranean perspective. ICBEE 2010-2nd International Conference on Chemical, Biological and Environmental Engineering, Proceedings, p.48-51, art. no. 5652332 (2010).

[4] Bonanno, A., Franzitta, V., Muzio, F.P., Trapanese, M. - A multiphysics approach to the design of a seawave energy conversion system. Proceedings of ICSET, Singapore, 2008,p.p. 665 668

[5] Di Dio, V., Franzitta, V., Muzio, F., Scaccianoce, G., Trapanese, M. - The use of sea waves for generation of electrical energy and hydrogen. MTS/IEEE Biloxi - Marine Technology for Our Future: Global and Local Challenges, OCEANS, 2009, art. no. 5422319.

[6] Sorrentino, G., Scaccianoce, G., Morale, M., Franzitta, V. The importance of reliable climatic data in the energy evaluation. Energy 2012.

[7] Trapanese, M., Viola, A., Franzitta, V. Description of hysteresis of nickel metal hybride battery. IECON 2012, 38th Annual Conference on IEEE Industrial Electronics Society, Montreal, Canada, pp. 967-970.

[8] Franzitta, V., Viola A., Trapanese M.; Description of hysteresis in Lithium battery by classical Preisach model, Advanced Materials Research Vols. 622-623 (2013) pp 1099-1103.

[9] Ciulla G., Franzitta V.; Lo Brano V., Viola A., Trapanese M., Mini Wind Plant to Power Telecommunication Systems: a Case Study in Sicily, Advanced Materials Research Vols. 622-623 (2013) pp 1078-1083.

[10] Trapanese M., A model of a linear synchronous motor based on distribution theory, J App Phys, Vol.111 (2012), Article number07E731.

[11] Trapanese M, "Noise enhanced stability in magnetic systems", J. App. PhysVolume 105, Issue 7, 2009, Article number 07D313.

[12] Cirrincione M., Miceli R., Galluzzo G.R., M. Trapanese, Preisach function identification by neural networks, IEEE Transactions on Magnetics Volume 38, Issue 5 I, (2002), Pages 2421-2423

[13] ISO, ISO/DP 10551 "Assessment of the influence of the thermal environment using subjective judgement scales. International Standard Organization 1993

[14] Takagi, T. and Sugeno, M.. Fuzzy Identification of Systems and Its Application to Modelling and Controls. IEEE Transactions on Systems, Man and Cybernetics 1985 ,SMC-15,1. 